\title{
Anthropometry Survey of Nigerian Occupational Bus Drivers to Facilitate Sustainable Design of Driver's Workplace
}

\author{
Onawumi Ayodele Samuel1*', Dunmade Israel11, Fajobi Moses² \\ ${ }^{1}$ Department of Mechanical Engineering, Covenant University, Ota, Nigeria \\ ${ }^{2}$ Ladoke Akintola University of Technology, Ogbomoso, Nigeria \\ Email: "ayodele.onawumi@covenantuniversity.edu.ng
}

Received 5 March 2016; accepted 7 May 2016; published 10 May 2016

Copyright (C) 2016 by authors and Scientific Research Publishing Inc.

This work is licensed under the Creative Commons Attribution International License (CC BY).

http://creativecommons.org/licenses/by/4.0/

(c) (i) Open Access

\begin{abstract}
Driving is a highly demanding and responsible job in which both the driver and passengers are exposed to several occupational risks. However, poor design of driver's workplace is a major risk factor responsible for the uncomfortable conditions which operators of this highly technological system are exposed to especially when engaged in long distance driving. This study aimed at developing anthropometric model for business bus drivers in Nigerian which would facilitate sustainable design of driver's workplace. A sample size of 161 drivers was randomly selected among strata of operators of buses in selected motor parks in the study area for the ergonomic study. Twelve anthropometric data were collected and analysed to obtain their 5th, 50th and 95th percentiles with which the anthropometric model were developed. Anthropometric model developed from 1932 data points was presented in forms of table showing measurement of sitting driver's body parts in his workspace indicating design for average as well as extremities of 5th and 95th percentiles. The model represents a database from which designers, manufacturers of equipment, machine, automobiles and household goods can obtain relevant body measurement of the population under study in relation relevant to specific product feature and for development of sustainable workspace design.
\end{abstract}

\section{Keywords}

Anthropometry, Workspace, Bus Driver, Ergonomics, Sustainable Design

\footnotetext{
"Corresponding author.
}

How to cite this paper: Samuel, O.A., Israel, D. and Moses, F. (2016) Anthropometry Survey of Nigerian Occupational Bus Drivers to Facilitate Sustainable Design of Driver's Workplace. World Journal of Engineering and Technology, 4, $176-182$. 


\section{Introduction}

Human body characteristic has become uniquely an important research area due to demand it poses on wears, furniture, workspace, engineering facilities and design of all manually operated systems. Among other studies of biological systems, anthropometric survey is an area that is rarely research in spite of its significance to the comfort, safety and performance of human operator of any facility. Anthropometry is the science of measurement and the art of application that establishes the physical geometry, mass properties, and strength capabilities of the human body. It is concerned with the scientific study of human subjects for the development of standards and evolving of specific demands associated specifically with manufactured goods and services to enhance product usability and suitability for the user population [1]-[3]. The applications of anthropometry in workplace design cannot be over emphasised which involve evaluation of postures, specification between controls and human operator/surrounding equipment as well as biomechanical analysis of forces and torque [4]-[6]. The least expectation from ergonomic designed workplace is to be able to accommodate extreme users typically from a 5th percentile woman to a 95th percentile man. Anthropometric data have varied uses the design of virtually every equipment, tool, automobile, clothing, shoes etc. that are being used or operated upon by human being. Also in public health including the evaluation of nutritional status, cancer studies, as a risk factor for coronary heart disease (CHD) [7].

It has been found that the taxi cabs used in Nigeria for public transport are in varieties of models in several variety of models sourced from advanced countries such as United State of America (USA), Germany, Japan, France, Europe and other developing countries like China, South Africa and India. These vehicles evidently were designed without due consideration for the peculiarities of anthropometric variable of Nigeria user population [8]. Ghosh et al. in their comparative study of the variability of anthropometric data among two communities observe that some of the variables such abdominal disposition differs significantly which suggest the high level of sensitivity that these morphological features assume [9].

The current ergonomic challenges faced by generally developing nations and Nigeria in particular include the absence of sustainable and structured anthropometric data bank. A number of anthropometric surveys of Nigerian available in literature are in pockets of research outputs with little or no consideration for implementation.

The automotive industry strongly encourages research in the field of objective comfort assessment, of seat and the related postures [10] [11]. Despite the efforts of several automobile manufacturers to develop new safe and user friendly vehicle workplace which increases its usability in terms of seat comfort, ease of reach of other in-vehicle's components, there is still a prevalence of work related musculoskeletal disorders (WRMDs) commonly reported among occupational drivers [12] [13]. Some other important factors that should be considered in the design of in-vehicle elements are related to human body dimensions of the drivers particularly in designing of automobile seat, dashboard, steering wheel, pedals, knobs, levers, and doors [14]-[17].

This work seeks to make further contribution to such efforts and to create an anthropometric database that finds useful applications in the design of bus driver's workspace. Ergonomics design of automobile is highly essential in the choice of model of vehicle that can be acceptable to Nigeria user population and in the legislation regarding importation of automobile in to the country [8] [13].

\section{Materials and Method}

A proportionate random sampling was done from each of the six major bus stations in the South western part of Nigeria. The sample size considered was determined using the procedures outlined in International Standard Organization (ISO) 15535 [17]. A sample size of one hundred and sixty-one bus drivers was selected for the study. Fifteen (15) anthropometric variables relating to seating posture were measured and characterised. The procedure for taking anthropometric measurement of subjects is quite technical and it requires the use of three trained enumerators and reliable anthropometric equipment. All measurements were taken with subject. Linear measurements considered in three dimensional plane as follows: 1) Sagittal Plane-Vertical Dimensions (e.g. Sitting Height Normal, Sitting Height Erect, Eye Height Sitting, Shoulder Height Sitting, 2) Sagittal Plane - Horizontal Dimensions (e.g. Forearm Hand Length Buttock-Popliteal Length, Buttock-Knee Length, Anterior Arm Reach; and 3) Frontal Plane (e.g. Shoulder Breadth, Elbow-to-Elbow Breadth, Hip Breadth Sitting, Kneeto-Knee Breadth, Foot Breadth, were all measured in centimetres while weights and ages are recorded in kilograms $(\mathrm{kg})$ and years $(\mathrm{yr})$ respectively. Four enumerators who have received adequate training on the process and procedure as well as the use of the equipment involved were used in conduct of the study. Likewise, the 
subjects were given a brief but well packaged orientation just before commencement of the measurement at their bus garages to inform them on objectives and benefits of the survey. Demographic characteristics and other personal details of the subjects were collected using structure questionnaire. The equipment which was used for the measurements includes stadiometer, a variable anthropometer, anthropometric seat, graduated measuring tape, and a bathroom weighing scale. As part of the procedure the subjects were asked to stand on the platform of the stadiometer and the pointer is moved to obtain the stature of each subject and in turn sit on the anthropometric seat, its arms were adjusted according to the subject's height and measurement was recorded from the vertical scale. In a similar form, other measurements were recorded in sitting and standing postures with the help of anthropometer. The measurements were evaluated on descriptive statistics such as the mean, standard deviation (sd), range and 5th, 50th, 95th percentiles using Excel Microsoft and STATA 11.0 data processing tools.

\section{Results and Discussion}

The population under study was absolutely male dominant with age range of 20 - 60 years, over 60 percent were 30 years and above which suggests relatively matured working population and married being 93\%. Less than $1 \%$ has higher education certificate while only fifty-two percent of the driver's school certificate holder. This could have significantly adverse implication on driver's level of understanding of road safety rule, regulations and repairs and maintenance instructions. The average stature of the respondents is about $176 \mathrm{~cm}(\mathrm{sd}=5.16)$ and the 95 percentile of the standing height is $186 \mathrm{~cm}$. Majority of the respondents (95\%) weigh less than $85 \mathrm{~kg}$ with mean weight of $74 \mathrm{~kg}(\mathrm{sd}=6.7)$. Table 1 shows the anthropometric measurement of the drivers arranged according to order of planes (Sagittal Plane-Vertical Dimension (I), Sagittal Plane-Horizontal Dimension (II), Frontal Plane III) and weight (IV). This represent anthropometric model for the commercial bus drivers in the study area. A comparison of the model with similar models obtained for molue drivers [18], taxi drivers [8]. Ismail et al. show no significant difference at $\mathrm{p}=0.05$ for all the variables considered [19] (Table 2). It is important to note that all the subjects in the surveys were from the same geo-political zone of Nigeria. However, a further comparison of the model with those of other study areas specifically the South West [18] and SouthEastern [20] show significant differences $(p=0.05)$ at some of anthropometric variables as statures, sitting height normal, and elbow rest height, buttock knee length and hip length (Table 3). This suggests that the influence of ethnicity cannot be overruled in anthropometric modelling. Such effect may however, fizzle out in the face of multi-ethnic population as found in capital cities and other commercial hubs of the country.

Table 4 presents the comparison of the mean ratio of buttock popliteal length to stature of different population and group. This ratio was specifically considered because of its direct application to design of seat. The activities of automobile driver is carried out in sitting posture and for many tasks in other occupation sitting is more common and convenient than any other posture. For design of driver's seat, it necessary to consider buttock popliteal length of the operator to obtain comfortable seat depth. The mean ratio obtained for south western Nigeria are almost the same possibly because the population under consideration are drivers. Significant difference exists in the case of passenger and agricultural workers having mean rations 0.3001 and 0.2962 respectively. The case of other nations there is similar in the mean ratios of Russia and Germany however both are considerably deferent from that of the present study. This suggests the need for adjustable mechanism of the seat depth which is conspicuously missing in the seat system of the busses imported into Nigeria.

The applications of anthropometric variable in the design of in-vehicle of bus are shown in Table 5. Mismatch between the characteristics of driver workspace and demands of human operators have resulted to musculoskeletal disorders (MSDs) and associated etiological effects. For instance a good number of the bus drivers patronises local herbals and hawkers of concussions to get medication for pains, strains and discomforts experienced after the day's work. Cumulative Trauma Syndrome (CTS) have also been related to awkward postural challenges occasioned by poor design of seat system of the buses. About sixty-eight percent of the buses operated by the driver had failed seat adjustable features hence constraining them awkward posture which they had to maintain for as long as the driving lasts. Also noted was that eighty-five percent of the vehicles was used foreign vehicles (refers to as Tokunbo) some of which were in the state of disused imported into the country. Where there is no functional policy guiding importation of automobile these Tokunbos find easy entry into nation market. Price variation between brand new bus and Tokunbo of the same mode is very large enough to influence the choice of an average Nigerian majority of who live below two dollars per day. Prevalence of discomfort and other musculoskeletal disorder renders the workplace of the operator unsustainable needing modifications. Some 
Table 1. Anthropometric data of bus operators $(n=161)$.

\begin{tabular}{|c|c|c|c|c|c|c|c|}
\hline & \multirow{2}{*}{ Anthropometric Variables } & \multirow{2}{*}{ Mean } & \multirow{2}{*}{ Std. Dev } & \multirow{2}{*}{ Range } & \multicolumn{3}{|c|}{ Percentile } \\
\hline & & & & & 5th & 50th & 95th \\
\hline \multirow{7}{*}{ I } & Stature & 176.12 & 6.17 & 21.8 & 167.6 & 175.6 & 185.9 \\
\hline & Sitting Height Normal & 79.32 & 4.31 & 16.8 & 72.7 & 79.3 & 85.0 \\
\hline & Sitting Height Erect & 83.36 & 6.65 & 27.4 & 75.0 & 83.2 & 93.6 \\
\hline & Shoulder Height Sitting & 57.54 & 2.55 & 9.7 & 53.9 & 57.3 & 61.5 \\
\hline & Shoulder-Elbow Length & 37.26 & 2.26 & 7.7 & 34.0 & 37.0 & 40.8 \\
\hline & Thigh Clearance Height & 14.06 & 1.38 & 4.49 & 12.1 & 13.9 & 16.1 \\
\hline & Popliteal Height Sitting & 49.39 & 2.02 & 6.79 & 46.3 & 49.3 & 52.3 \\
\hline \multirow{4}{*}{ II } & Buttock-Popliteal Length & 48.97 & 2.57 & 10.5 & 45.7 & 48.6 & 53.2 \\
\hline & Buttock-Knee Length & 58.89 & 2.88 & 13.6 & 55.0 & 59.0 & 63.1 \\
\hline & Anterior-Arm Reach & 89.19 & 3.99 & 15.3 & 83.7 & 89.2 & 95.4 \\
\hline & Thumb-Tip Reach Sitting & 81.44 & 3.53 & 12.7 & 76.7 & 80.9 & 87.2 \\
\hline \multirow{3}{*}{ III } & Shoulder Breadth & 45.42 & 3.25 & 10.6 & 40.4 & 45.1 & 50.1 \\
\hline & Hip Breadth & 37.95 & 3.62 & 15.7 & 32.8 & 37.9 & 42.7 \\
\hline & Maximum Body Breadth & 46.1 & 3.2 & 11.2 & 41.0 & 46.2 & 50.8 \\
\hline IV & Weight & 74.05 & 6.70 & 31.5 & 61.7 & 73.6 & 85.1 \\
\hline
\end{tabular}

All dimensions were measured in centimetres $(\mathrm{cm})$ except weight which is in kilogram $(\mathrm{kg})$.

Table 2. Comparison of anthropometric data of bus operators with past related works obus and taxicab operators' anthropometry in Nigeria.

\begin{tabular}{ccccccccccc}
\hline Anthropometric Measurement & \multicolumn{3}{c}{ Ajayeoba [18] } & \multicolumn{3}{c}{ Onawumi [8] } & \multicolumn{3}{c}{ Present study } \\
\cline { 2 - 10 } & 5th & 50 th & $95^{\text {th }}$ & 5 th & 50 th & $95^{\text {th }}$ & 5 th & 50 th & 95 th \\
\hline Shoulder Height Sitting & 54.0 & 57.1 & 60.2 & 49.8 & 56.2 & 65.2 & 53.9 & 57.3 & 61.5 \\
Shoulder-Elbow Length & 33.5 & 36.2 & 38.9 & 35.14 & 37.90 & 42.90 & 34.0 & 37.0 & 40.8 \\
Shoulder Breadth & 40.6 & 42.8 & 45.0 & 40.24 & 44.35 & 50.86 & 40.4 & 45.1 & 50.1 \\
Sitting Height Normal & NA & NA & NA & 72.9 & 79.5 & 85.37 & 72.7 & 79.3 & 85.0 \\
Sitting Height Erect & NA & NA & NA & 76.2 & 83.4 & 88.87 & 75.0 & 83.2 & 93.6 \\
Buttock-Knee Length & 54.9 & 58.1 & 61.3 & 54.0 & 60.2 & 64.7 & 55.0 & 59.0 & 63.1 \\
Buttock-Popliteal Length & 45.8 & 48.9 & 51.9 & 40.04 & 48.05 & 53.80 & 45.7 & 48.6 & 53.2 \\
Thigh Clearance Height & 11.5 & 13.3 & 15.0 & 11.5 & 13.9 & 17.40 & 12.1 & 13.9 & 16.1 \\
Popliteal Height Sitting & 47.4 & 49.8 & 52.1 & 38.47 & 42.35 & 47.93 & 46.3 & 49.3 & 52.3 \\
Thumb-Tip Reach Sitting & 75.9 & 79.9 & 83.8 & N/A & N/A & N/A & 76.7 & 80.9 & 87.2 \\
Anterior-Arm Reach & 82.2 & 86.4 & 90.5 & 75.70 & 86.20 & 95.77 & 83.7 & 89.2 & 95.4 \\
Stature & 166.8 & 173.3 & 179.7 & 161.30 & 172.00 & 182.76 & 167.6 & 175.6 & 185.9 \\
Hip Breadth & 31.8 & 34.9 & 38.1 & 31.84 & 35.80 & 39.60 & 32.8 & 37.9 & 42.7 \\
Maximum Body Breadth & 41.8 & 44.6 & 47.5 & 42.0 & 47.1 & 54.57 & 41.0 & 46.2 & 50.8 \\
Weight & N/A & N/A & N/A & 58.81 & 68.00 & 88.07 & 61.7 & 73.6 & 85.1 \\
\hline
\end{tabular}

All variables were measured in centimetres (cm). 
Table 3. Comparison of anthropometric data of automobile operators from related works in Nigeria.

\begin{tabular}{ccccccccccc}
\hline \multirow{2}{*}{ Anthropometric Measurement } & \multicolumn{3}{c}{ Ismaila et.al [19] } & \multicolumn{3}{c}{ Onuoha [20] } & \multicolumn{3}{c}{ Present study } \\
\cline { 2 - 10 } & 5th & 50 th & 95 th & 5 th & 50 th & 95 th & 5 th & 50 th & 95 th \\
\hline Shoulder Height Sitting & N/A & N/A & N/A & 48.4 & 55.3 & 57.7 & 53.9 & 57.3 & 61.5 \\
Shoulder-Elbow Length & N/A & N/A & N/A & 26.8 & 31.0 & 44.5 & 34.0 & 37.0 & 40.8 \\
Shoulder Breadth & N/A & N/A & N/A & 38.6 & 44.3 & 55.7 & 40.4 & 45.1 & 50.1 \\
Sitting Height Normal & N/A & N/A & N/A & N/A & N/A & N/A & 72.7 & 79.3 & 85.0 \\
Sitting Height Erect & 76.9 & 83.5 & 93.0 & 69.4 & 83.5 & 92.9 & 75.0 & 83.2 & 93.6 \\
Buttock-Knee Length & 58.4 & 62.1 & 67.7 & 49.1 & 58.3 & 63.0 & 55.0 & 59.0 & 63.1 \\
Buttock-Popliteal Length & 44.4 & 51.1 & 60.8 & 42.6 & 49.1 & 53.5 & 45.7 & 48.6 & 53.2 \\
Thigh Clearance Height & 11.9 & 14.1 & 16.9 & 11.4 & 13.6 & 15.7 & 12.1 & 13.9 & 16.1 \\
Popliteal Height Sitting & N/A & N/A & N/A & 39.5 & 43.3 & 52.1 & 46.3 & 49.3 & 52.3 \\
Thumb-Tip Reach Sitting & N/A & N/A & N/A & NA & NA & NA & 76.7 & 80.9 & 87.2 \\
Anterior-Arm Reach & N/A & N/A & N/A & 75.3 & 81.2 & 91.2 & 83.7 & 89.2 & 95.4 \\
Stature & 158.8 & 172.5 & 190.8 & 158.9 & 163.6 & 176.6 & 167.6 & 175.6 & 185.9 \\
Hip Breadth & 29.0 & 36.4 & 46.4 & 28.5 & 30.8 & 35.6 & 32.8 & 37.9 & 42.7 \\
Maximum Body Breadth & 33.7 & 46.0 & 64.0 & N/A & N/A & N/A & 41.0 & 46.2 & 50.8 \\
Weight & N/A & N/A & N/A & 41.3 & 56.3 & 66.3 & 61.7 & 73.6 & 85.1 \\
\hline
\end{tabular}

All variables were measured in centimetres $(\mathrm{cm})$.

Table 4. Comparison of buttock-popliteal length to stature ratio with other ethnic populations of the world.

\begin{tabular}{cccc}
\hline Study & & Mean Ratio & Source \\
\hline South Western Nigeria & Bus drivers & 0.2768 & Present study \\
South Western Nigeria & Molue Bus drivers & 0.2822 & Ajayeoba [18] \\
South Western Nigeria & Taxi cab drivers & 0.2794 & Onawumi [8] \\
South Western Nigeria & Passengers in Busses & 0.2962 & Ismaila et al. [19] \\
South Eastern Nigeria & Agricultural workers & 0.3001 & Onuoha [20] \\
Britain & Male Adult & 0.2845 & Marras and Karwowsk [21] \\
Germany & Male Adult & 0.2834 & Marras and Karwowsk [21] \\
Russia & Male Adult & 0.2592 & Marras and Karwowsk [21] \\
\hline
\end{tabular}

drivers end up deforming the workspace through some form of ill-informed adjustments and reworks (through fabrication of certain attachment) done on some elements of the workspace. Result of this survey bring to light the needed database that manufacturer of automobile can use in manufacture of user friendly driver workplace.

\section{Conclusion}

It was observed that Nigeria had been made a dumping ground for disused items including automobiles the picture that the present government ought to address with deep sense of responsibility. There is great need to enact and enforce importation policy on automobile in Nigeria. This would drive the auto manufacturers who like to trade with country to take up responsibility of supporting research in the area of ergonomic suitability of their product to Nigeria users which effort will impact positively on the comfortable, safe, and performance of operator of the engineering system. Alongside with the demographic content of the population of Nigeria, government should consider including the collection of anthropometric data of different age structure of her population. Design 
Table 5. Applications of body dimensions in the in-vehicle design of bus.

\begin{tabular}{cccc}
\hline Anthropometric Variable & Mean $\left(50^{\text {th }}\right.$ percentile $)$ & SD & Application In-vehicle Variables \\
\hline Popliteal height sitting & 49.39 & 2.02 & Seat height \\
Hip breadth sitting & 37.95 & 3.62 & Seat width \\
Buttock-popliteal length & 48.97 & 2.57 & Seat length \\
Shoulder height, sitting & 57.54 & 2.55 & Back-rest length \\
Shoulder breadth & 45.42 & 3.25 & Back-rest width \\
a. Anterior arm reach sitting & 89.19 & 3.99 & Dashboard-backrest length \\
b. Thumb-tip reach sitting & 81.44 & 3.53 & \\
c. Buttock-knee length & 58.89 & 2.88 & Steering-wheel external diameter \\
Anterior arm reach sitting & 89.19 & 3.99 & Thigh clearance (steering wheel-seat height) \\
Thigh height sitting & 14.06 & 1.38 & Driver's door height \\
Stature & 176.12 & 6.17 & Driver's door width \\
Max. body breadth & 46.1 & 3.2 & Ground-to-driver's door height \\
Stature & 176.12 & 6.17 & Elbow clearance \\
Popliteal height sitting & & & Seat-pedal length \\
Popliteal height sitting & 49.39 & 2.02 & Seat Adjustment \\
Sitting height normal & 49.39 & 2.02 & Hounded front edge seat width \\
Buttock-knee length & 79.32 & 6.31 & \\
\hline
\end{tabular}

for sustainability of a vehicle with careful consideration of the physical limitations of the driver is a requirement for user-friendly, comfortable and effective drivers-vehicle system. This enhances acceptability, performance and productivity among bus operators and encourages healthy competition within automotive industry. A public-private partnership (PPP) arrangement is suggested for successful development of national anthropometric database which will involve representative of organised drives' associations, manufacturer, researchers and information scientists.

\section{References}

[1] Agrawal, K.N., Singh, R.K.P. and Satapathy, K.K. (2010) Anthropometric Considerations of Farm Tools/Machinery Design for Tribal Workers of Northern Indian. Agricultural Engineering International: CIGR Journal, 12, 143-150.

[2] Caragliu, B. (2006) Fitness for Drivers. G. Ital Med Lav Ergonomics, 28, 82-84.

[3] Muzammil, M., Rizvi, S.A.H., Hassan, F. and Hassan, S.N. (2007) Anthropometric Data with Special Reference to the Indian Needs-An Overview. Industrial Engineering Journal-PR, 87.

[4] Hertzberg, H.T.E. (1972) Engineering Anthropology: Human Engineering Guide to Equipment Design. McGraw-Hill Company, Washington DC.

[5] Pheasant, S. (1986) Body Space: Anthropometry, Ergonomics and Design. Taylor \& Francis, London.

[6] Del Prado-Lu, J.L. (2007) Anthropometric Measurement of Filipino Manufacturing Workers. Industrial Ergonomics, 37, 497-503.

[7] Wang, J. (2003) Waist Circumference: A Simple, Inexpensive, and Reliable Tool That Should Be Included as Part of Physical Examinations in the Doctor's Office. American. Journal of Clinical Nutrition, 78, 902-903.

[8] Onawumi, A.S. and Lucas, E.B. (2012) Ergonomic Investigation of Occupational Drivers and Seat Design of Taxicabs in Nigeria. ARPN Journal of Science and Technology, 2, 214-220.

[9] Ghosh, J.R., Khatoon, Z., Bhattacharjee, P. and Bandyopadhyay, A.R. (2005) A Comparative Study on Anthropometric Variables in Two Communities of West Bengal, India. Anthropologist, 7, 217-219.

[10] Gyi, D.E., Porter, J.M. and Robertson, N.K.B. (1998) Seat Pressure Measurement Technologies: Consideration for 
Their Evaluation. Applied Ergonomics, 27, 85-91.

[11] Nishith, M., Kajaria, N., Gulati, N. and Beriya, A. (2014) Framework to Analyse Automotive Interiors with a Focus on Ergonomics. 4, 309-315.

[12] Peter, L., Joseph, R., Gregory, R. and William S.K. (2014) Objective Classification of Vehicle Seat Discomfort. Ergonomics.

[13] Nishint, S. and Apurava, A.A. (2015) Literature Review on Ergonomics of Indian Seat Design for Passenger Comfort and Safety. International Journal of Technology Innovations and Research, 15.

[14] Gilmore, B.J., Bucciaglia, J., Lowe, B., You, H. and Freivalds, A. (1997) Bus Operator Workstation Evaluation and Design Guidelines, TCRP Report F-4, Transportation Cooperative Research Program (TCRP). Transportation Research Board US. www.tradeshall.org.znz/stagecoach/cabergon.html

[15] Ebe, K. and Criffin M.J. (2001) Factors Affecting Static Seat Cushion Comfort. Ergonomics, 44, 901-921.

[16] Lucas, E.B. and Onawumi, A.S. (2012) Ergonomic Evaluation of In-Vehicle Interface Design of Taxicabs in Nigeria International Journal of Engineering Research and Applications, 3, 566-572.

[17] International Standard (2001) ISO 15535, Genaral Requirements for the Establishment of Anthropometric Database.

[18] Ajayeoba, A.O. and Adekoya, L.O. (2009) Ergonomic Appraisal of Aisles of Molue Buses in Nigeria. The Ergonomia IJE and HF, 30, 309-317.

[19] Ismaila, S.O., Akanbi, D.G., Adunkle, N.O., Adetunji, O.R. and Kuye, S.I. (2010) An Ergonomics Assessment of Passengers Seats in South Western Nigeria. SIGURNOST, 52, 329-334.

[20] Onuoha, S.N., Idike, F.I. and Oduma, O. (2012) Anthropometry of South Eastern Nigeria Agricultural Workers. International Journal of Engineering and Technology, 2.

[21] Marras, S. and Karwowski, W. (2006) Fundamental and Assessment Tools for Occupational Ergonomic. 2nd Edition, Taylor and Francis Group, LLC, 3-17. 